\title{
MICROBIOLOGIA DE QUEIJO TIPO MINAS FRESCAL PRODUZIDO ARTESANALMENTE
}

\author{
MICROBIOLOGY OF HOMEMADE MINAS FRESCAL CHEESE
}

\author{
Andrea Pinto Loguercio ${ }^{1}$ José Antônio Guimarães Aleixo
}

RESUMO

Com o objetivo de avaliar as condições higiênicosanitárias do queijo Minas Frescal produzido artesanalmente em Cuiabá - MT, foi realizada análise microbiológica de trinta amostras obtidas em dois pontos de comercialização. A análise microbiológica consistiu da contagem em placas de Staphylococcus aureus $e$ da contagem estimativa de coliformes totais, fecais e Escherichia coli pela técnica do NMP-3 tubos. Na determinação de coliformes fecais, 28 amostras (93,33\%) apresentaram número mais provável $(\mathrm{NMP})>10^{2} \mathrm{NMP} / \mathrm{g} e$ somente duas amostras $(6,67 \%)$ estavam dentro dos padrões legais exigidos. Na contagem de S. aureus, em 29 amostras $(96,67 \%)$ obteve-se valores superiores a $10^{3} \mathrm{ufc} / \mathrm{g}$, estando apenas 1 amostra (3,33\%) em conformidade com o padrão legal. Conclui-se que uma maior atenção deve ser dada pelas autoridades sanitárias em relação à permissão de fabricar $e$ comercializar esse produto, uma vez que ele representa risco à saúde dos consumidores.

Palavras-chave: queijo Minas Frescal,coliformes, Staphylococcus aureus, Escherichia coli.

\section{SUMMARY}

To evaluate the hygienic-sanitary quality, thirty samples of the homemade "Minas Frescal" cheese were obtained from two places of commercialization in Cuiabá - MT, Brazil during two months. The samples were submitted to the following microbiological analysis: Staphylococcus aureus counting, total and fecal coliforms and Escherichia coli by MPN method. In the determination of fecal coliforms, 28 samples (93.33\%) showed values greater than $10^{2} \mathrm{MPN}$ per $\mathrm{g}$, and only two samples $(6.67 \%)$ were within the national microbiological standard. Regarding to S. aureus, 29 samples (96.67\%) were higher than $10^{3} \mathrm{CFU} / \mathrm{g}$, and only one sample (3.33\%) was in accordance with the national microbiological standard. The sanitary authorities should carefully consider the permission of the production and commercialization of this product, due to the risks to the consumer's health.
Key words: Minas Frescal cheese, coliforms, Staphylococcus aureus, Escherichia coli.

\section{INTRODUÇÃO}

O queijo Minas Frescal é um produto que tem ampla aceitação comercial e que faz parte do hábito alimentar da população, na maioria das regiões do país. Apesar da legislação brasileira exigir a utilização de leite pasteurizado no seu preparo, é bastante freqüente a comercialização do produto que não atende a esta especificação legal (PEREIRA et al., 1991).

Quando este produto é fabricado de forma artesanal, por pessoas não treinadas, pode ocorrer a contaminação por diversos microrganismos, comprometendo tanto a sua qualidade como a segurança da saúde do consumidor. Por este motivo, as práticas higiênicas devem ser observadas com rigor, para prevenir uma possível contaminação ou recontaminação do produto. Além disso, por não ser maturado, é um produto perecível, devendo ser consumido rapidamente após curta estocagem em ambiente refrigerado (SILVA \& LEITÃO, 1980).

A ingestão de queijos com condições inadequadas para consumo pode trazer graves conseqüências para a população, sendo, portanto, um problema de Saúde Pública. De acordo com o anexo I da Portaria 451 do DINAL (BRASIL, 1997), o queijo Minas Frescal deve atender aos seguintes padrões microbiológicos: número mais provável (NMP) máximo de $10^{2} / \mathrm{g}$ para coliformes fecais e

\footnotetext{
${ }^{1}$ Engenheiro Agrônomo, Mestrando em Ciência e Tecnologia Agroindustrial, Universidade Federal de Pelotas (UFPel).

${ }^{2}$ Médico Veterinário, PhD., Professor Titular, Centro de Biotecnologia, UFPel, Campus Universitário, 96019-900 Capão do Leão, RS. Email: biotjaga@ufpel.tche.br. Autor para correspondência.
} 
NMP ou contagem direta em placa (máximo) de $10^{3} / \mathrm{g}$ para Staphylococcus aureus, objetivando levar ao consumidor um produto de boa qualidade higiênico-sanitária.

Os grupos de coliformes totais e fecais colonizam o trato intestinal de animais de sangue quente, incluindo os humanos, e têm sido empregados como indicadores de qualidade higiênica por muitos anos (CALCI et al., 1998). Apesar das controvérsias com relação aos microrganismos mais representativos da qualidade sanitária de um produto alimentício, os coliformes em geral, a Escherichia coli e os enterococos, têm merecido maior consideração (SHARF, 1972). De acordo com ANDREWS et al. (1979), a despeito dos coliformes serem ou não inadequados indicadores da segurança microbiológica da água e alimentos, os membros desse grupo continuam sendo usados internacionalmente para esse fim.

FRANK et al. (1977) correlacionaram a presença de coliformes fecais em queijo tipo Camembert, com a ocorrência de $\boldsymbol{E}$. coli enteropatogênica, o que também foi demonstrado por FRANK \& MARTH (1978). Segundo SANTOS et al. (1995), a Escherichia coli enterotoxigênica é a causa comum de "diarréia de viajante". Algumas cepas, ao serem ingeridas com alimentos, crescem no intestino e produzem toxinas que originam hipersecreção no intestino delgado; a luz intestinal é distendida pelo líquido, provocando hipermotilidade e diarréia que duram alguns dias (1 a 3 dias). O período de incubação é de 24 a 72 horas. Ocorre diarréia, vômitos, mas não apresenta quadro febril.

Os estafilococos podem produzir doença tanto por sua capacidade de multiplicação e disseminação ampla nos tecidos, como pela produção de muitas substâncias extra-celulares, como a enterotoxina, que é uma causa importante de intoxicação alimentar, sendo produzida, principalmente, quando certas cepas de Staphylococcus aureus crescem em alimentos contendo carboidratos e proteínas (FRAZIER \& WESTHOFF, 1988). Enquanto as células de $\boldsymbol{S}$. aureus são termolábeis e facilmente eliminadas por processos moderados de temperatura, as enterotoxinas são termoestáveis e resistentes a temperaturas normalmente utilizadas no processamento de produtos lácteos (FREITAS \& MAGALHÃES, 1990).

O $S$. aureus é freqüentemente pesquisado em alimentos, sendo o queijo, um dos principais veículos causadores de toxinfecção alimentar, pois sua presença está associada a práticas de higiene e manipulação inadequadas (REIBNITZ et al., 1998).
SABIONI et al. (1994) citam casos de intoxicação estafilocócica causada por queijo Minas Frescal, assim como ANUNCIAÇÃO et al. (1994), que relataram a presença de enterotoxina estafilocócica também em queijo Minas Frescal em todas as amostras testadas com contagens de $10^{4} \mathrm{ufc} / \mathrm{m} \ell$. Apesar de ser quase incomum a fatalidade da intoxicação alimentar estafilocócica, ela ocorre ocasionalmente em indivíduos debilitados imunologicamente, idosos e crianças em tenra idade (GONÇALVES \& FRANCO, 1996).

O presente estudo teve como objetivo avaliar a qualidade higiênico-sanitária do queijo Minas Frescal produzido artesanalmente e comercializado em Cuiabá, através da investigação da carga de microrganismos indicadores em amostras coletadas em dois pontos de comercialização.

\section{MATERIAL E MÉTODOS}

Durante o período de setembro a novembro de 1997, as amostras de queijo tipo Minas Frescal foram adquiridas em dois pontos tradicionais na comercialização de produtos coloniais no centro de Cuiabá-MT. A cada amostragem, foi coletado um queijo de aproximadamente $200 \mathrm{~g}$ em cada um dos estabelecimentos, totalizando 30 amostras. As amostras foram transportadas para o laboratório em caixa de material isotérmico (isopor) contendo cubos de gelo e mantidas sob refrigeração até o momento das análises. Em nenhum caso, o tempo decorrido entre a coleta das amostras e o início da análise microbiológica ultrapassou a duas horas.

De cada amostra foram pesados, assepticamente, 25 gramas do produto e adicionados $225 \mathrm{~m} \ell$ de solução salina estéril $(\mathrm{NaCl} 0,85 \% \mathrm{p} / \mathrm{v})$ com $0,1 \%(\mathrm{p} / \mathrm{v})$ de Peptona (SSP), a fim de obter-se a diluição inicial $\left(10^{-1}\right)$, a qual foi homogeneizada em liqüidificador. Posteriormente, 1 mililitro desta diluição foi colocado num tubo contendo $9 \mathrm{~m} \ell$ de Solução Salina Peptonada (SSP) 0,1\%, obtendo-se a diluição $10^{-2}$ e tal procedimento foi repetido para obtenção das diluições $10^{-3}, 10^{-4}$ e $10^{-5}$.

Para determinação do Número Mais Provável (NMP) de coliformes totais, de cada diluição $\left(10^{-1}\right.$ a $\left.10^{-3}\right)$ do alimento em estudo, foram tomadas três porções de $1 \mathrm{~m} \ell$ cada e inoculadas, respectivamente, em três tubos contendo $10 \mathrm{~m} \ell$ de Caldo Lauril Sulfato Triptose (LST MERCK 10266) contendo um tubo de Durham invertido, obtendo-se três séries de três tubos. Foi utilizado um tubo controle do meio de cultura e outro controle do meio 
de cultura e diluente, os quais foram incubados em estufa a $35-37^{\circ} \mathrm{C}$, por $24-48$ horas. Os subcultivos positivos foram semeados em tubos contendo $8 \mathrm{~m} \ell$ de Caldo Verde Brilhante Bile 2\% (VB MERCK 5454) com tubo de Durham invertido, incubando-os a $35^{\circ} \mathrm{C}$, durante 24 a 48 horas. A prova foi considerada positiva somente quando se verificava turvação do meio e produção de gás nos tubos de Durham, dentro de um período de incubação máximo de 48 horas. A determinação quantitativa foi realizada de acordo com a técnica do NMP, recomendada pela American Public Health Association (VANDERZANT \& SPLITTSTOESSER, 1992).

Uma alçada de cada cultura foi tomada dos tubos positivos de LST e transferida para tubos de Caldo E. coli (EC MERCK 10765), contendo tubos de Durham invertidos, e incubados a $45,5^{\circ} \mathrm{C}$, em banho-maria, para determinação de coliformes fecais. Após a incubação por 24 a 48 horas foi realizada a leitura, e os tubos que apresentavam turvação do meio e produção de gás foram considerados positivos para bactérias do grupo coliforme fecal. Para cada diluição, o número de tubos positivos foi anotado e quantificado através da tabela de NMP (VANDERZANT \& SPLITTSTOESSER, 1992), determinando, assim, o NMP de bactérias coliformes fecais por grama de queijo analisado.

Os tubos positivos em Caldo EC foram semeados em placas contendo meio Ágar Eosina Azul de Metileno (EMB), segundo Levine (MERCK 1342) para pesquisa de Escherichia coli. As placas foram incubadas a $35-37^{\circ} \mathrm{C}$, por 24 horas. A partir das colônias típicas e isoladas de $\boldsymbol{E}$. coli crescidas no meio EMB, foram realizadas as provas bioquímicas de IMViC (indol, vermelho de metila/ VogesProskauer e citrato), de acordo com a técnica descrita por VANDERZANT \& SPLITTSOESSER, 1992.

Para a quantificação de Staphylococcus aureus utilizou-se o método de contagem "Spreadplate" em Agar Baird Parker (BP MERCK 5406), em duplicata, depositando-se $0,1 \mathrm{~m} \ell$ de cada diluição sobre a superfície do ágar e, com o auxílio de um bastão de vidro tipo "hockey" flambado, espalhou-se o inóculo por toda a superfície do meio até a completa absorção. As placas foram incubadas a $35-37^{\circ} \mathrm{C}$, por 24 a 48 horas. Foram selecionadas as placas contendo entre 20 e 200 colônias, selecionando as colônias típicas. A partir destas, foram selecionadas três colônias típicas de cada placa, que foram inoculadas em tubos contendo $1 \mathrm{~m} \ell$ de Caldo de Infusão Cérebro Coração (BHI _ MERCK 10493), os quais foram incubados a $35-37^{\circ} \mathrm{C}$, por 24 horas. A partir do subcultivo crescido em BHI, foram realizadas as seguintes provas bioquímicas: coagulase, catalase, coloração de Gram e termonuclease, quando necessárias (VANDERZANT \& SPLITTSOESSER, 1992).

\section{RESULTADOS E DISCUSSÃO}

Nas tabelas 1 e 2, estão apresentados os resultados dos exames microbiológicos de queijo tipo Minas Frescal comercializados na cidade de Cuiabá - MT, no período de setembro a novembro de 1997.

A tabela 1 mostra os valores máximos, mínimos e médios das contagens de $\boldsymbol{S}$. aureus e da enumeração de coliformes totais, coliformes fecais e E. coli das amostras de queijos. Como a legislação sanitária só apresenta padrões para dois destes microrganismos, a tabela 2 apresenta a conformidade destes resultados com a Portaria 451 do Ministério da Saúde (BRASIL, 1997), que considera o queijo Minas Frescal em desacordo com os padrões legais vigentes quando as contagens de coliformes fecais e $S$. aureus é superior a $10^{2}$ ufc/g e $10^{3} \mathrm{ufc} / \mathrm{g}$, respectivamente. Nota-se, através dos dados da tabela 2, que 28 amostras (93,33\%) encontravam-se com contagens acima do padrão para coliformes fecais e 29 amostras $(96,67 \%)$ apresentavam contagens superiores ao padrão legal aceitável para $S$. aureus. Esta mesma Portaria classifica como "Produto em condições higiênicosanitárias insatisfatórias", aqueles que apresentam a enumeração de coliformes fecais, entre outros microrganismos, acima dos limites estabelecidos nos padrões específicos e num valor máximo de até dez vezes esses limites, o que ocorreu com as 29 amostras pesquisadas; somente uma amostra de queijo $(3,33 \%)$ apresentou contagem de coliformes fecais superior a $10^{3} \mathrm{ufc} / \mathrm{g}$. Em relação à contagem de S. aureus, a Portaria descreve como "Produto em condições higiênico-sanitárias insatisfatórias" aquele

Tabela 1 - Contagens de microrganismos em 30 amostras de queijo tipo minas frescal comercializado em Cuiabá.

\begin{tabular}{lcccc}
\hline Contagem & C. totais (NMP/g) & C. fecais (NMP/g) & E. coli $(\mathrm{NMP} / \mathrm{g})$ & S. aureus $(\mathrm{ufc} / \mathrm{g})$ \\
\hline Mínima & $1 \times 10^{3}$ & $2 \times 10^{1}$ & $4 \times 10^{1}$ & $1 \times 10^{3}$ \\
Média & $1,8 \times 10^{3}$ & $8,5 \times 10^{2}$ & $6 \times 10^{2}$ & $3 \times 10^{4}$ \\
Máxima & $>2 \times 10^{3}$ & $>1 \times 10^{3}$ & $1 \times 10^{3}$ & $6 \times 10^{4}$ \\
\hline
\end{tabular}


Tabela 2 - Comparação das contagens de coliformes fecais e Staphylococcus aureus, em número de amostras e percentagens, de trinta amostras de queijo minas frescal com o padrão microbiológico existente (SVS/ MS, 1997)

\begin{tabular}{lcccc}
\hline Microrganismos & \multicolumn{2}{c}{ Dentro dos padrões } & \multicolumn{2}{c}{ Fora dos padrões } \\
\hline & N. ${ }^{\circ}$ & $\%$ & N. ${ }^{\circ}$ & $\%$ \\
Coliformes fecais & 2 & 6,67 & 28 & 93,33 \\
Staphylococcus aureus & 1 & 3,33 & 29 & 96,67 \\
\hline
\end{tabular}

que apresenta contagem de $S$. aureus de até dez vezes o limite do padrão legal, o que ocorreu com 5 amostras (16,67\%). Entretanto, 13 amostras $(43,33 \%)$ foram consideradas como "Produtos potencialmente capazes de causar enfermidades transmitidas por alimentos", pois apresentaram contagens de $\boldsymbol{S}$. aureus superior a dez vezes o limite estabelecido nos padrões específicos.

A presença de $\boldsymbol{E}$. coli em um alimento pode ser avaliada sob dois significados. Inicialmente, $\boldsymbol{E}$. coli, por ser uma enterobactéria, uma vez detectada no alimento, indica que este tem contaminação microbiana de origem fecal e portanto está em condições higiênicas insatisfatórias. O outro aspecto a ser considerado é que diversas linhagens de $\boldsymbol{E}$. coli são comprovadamente patogênicas para o homem e animais (FRANCO \& LANDGRAF, 1996). Uma ampla revisão sobre as condições sanitárias de produção e comercialização do queijo Minas Frescal é apresentada por PINTO et al. (1996). O nível de contaminação detectado neste trabalho revela que o consumo deste produto de fabricação artesanal em Cuiabá é um perigo constante e real para a saúde pública.

\section{CONCLUSÕES}

Os resultados experimentais deste trabalho demonstram que, para coliformes fecais, 93,33\% das amostras apresentaram condições higiênico-sanitárias insatisfatórias, de acordo com o padrão legal vigente, indicando sua contaminação direta ou indiretamente com material fecal, sendo classificadas como produtos impróprios para o consumo.

A presença de $\boldsymbol{S}$. aureus além dos limites aceitáveis em 96,67\% das amostras indica seu desacordo com o padrão legal vigente, sendo que em $43,33 \%$ destas amostras foram produtos classificados como potencialmente capazes de causar intoxicação alimentar. Devido à ocorrência de amostras positivas para $\boldsymbol{S}$. aureus, pode-se supor que o tratamento térmico do leite esteja sendo ineficiente, ou que esteja ocorrendo contaminação após este tratamento, devido à manipulação ou contato com superfícies não sanitizadas, ou, o que é mais comum em produções artesanais, esteja sendo utilizado o leite cru, não pasteurizado, na fabricação do queijo. Este fato está totalmente em desacordo com as recomendações do Ministério da Saúde e da Agricultura. Portanto, maior atenção deve ser tomada pelas autoridades sanitárias, uma vez que tais produtos colocam em risco a saúde do consumidor, além de comprometerem a qualidade e prazo de validade dos produtos.

\section{REFERÊNCIAS BIBLIOGRÁFICAS}

ANDREWS, W.H., DURAN, A.P., McCLURE, F.D. et al. Use of two rapid A-1 methods for the recovery of fecal coliforms and Escherichia coli from selected foods types. Journal of Food Science, Chicago, v.44, n.1, p.289 -293, 1979.

ANUNCIAÇÃO, L.L.C., LINARDI, W.R., CARMO, L.S. et al.. Production of staphylococcal Enteroxin A in white cheese. R Microbiol., São Paulo, v.5, n.1, p.68 -71, 1994.

BRASIL. Ministério da Saúde. Secretaria Nacional de Vigilância Sanitária de Alimentos - DINAL. Padrões Microbiológicos para produtos expostos à venda ou de alguma forma destinados ao consumo. Portaria n. $^{\circ} 451$ de 19 de setembro de 1997. Diário Oficial [da República Federativa do Brasil ], Brasília, p.21005-21012, 22 de setembro de 1997, Seção I.

CALCI, K.R., BURKHARDT III, W., WATKINS, W.D. et al. Occurrence of male-specific bacteriophage in fecal and domestic animal wastes, human feces and human-associated wastewaters. Applied and Envir Microbiol, v.64, n.12, p.5027-5029, dec, 1998.

FRANCO, B.D.G.M., LANDGRAF, M. Microbiologia dos alimentos. São Paulo : Atheneu, 1996. 182p.

FRANK, J.P., MARTH, E.H. Survey of soft and semisoft cheese for presence of fecal coliforms and serotypes of enteropathogenic Escherichia coli. Journal Food Protection, Ames, v.41, n.3, p.198-200, mar, 1978.

FRANK, J.P., MARTH, E.H., OLSON, N.F. Survival of enteropathogenic and nonpathogenic Escherichia coli during the manufacture of cammember cheese. Journal of Food Protection, Ames, v.40, n.12, p.835-842, dec, 1977.

FRAZIER, W.C., WESTHOFF, D.C. Food microbiology. 4 ed.. New York : Mc Graw-Hill, 1988. 494p.

FREITAS, M.A.Q., MAGALHÃES, H. Enterotoxigenicidade de Staphylococcus aureus isolados de vacas com mastite. R Microbiol., São Paulo, v.21, n.4, p.315-19, 1990.

GONÇALVES, P.M.R., FRANCO, R.M. Coliformes fecais, Salmonella e Staphylococcus aureus em queijo Minas Frescal. Rev Bras Ciência Vet, v.3, n.1, p.5-9, jan-abr, 1996. 
PEREIRA, M.L., LARA, M.A., DIAS, R.S. et al. Intoxicação por Staphylococcus aureus provocada por queijo "tipo Minas". Rev Microbiol, São Paulo, v.22, p.349-350, 1991.

PINTO, P.S.A., ANDRADE, N., SILVA, J. et al. Queijo Minas: problema emergente da vigilância sanitária. Higiene Alimentar, São Paulo, v.10, p.22-27, 1996

REIBNITZ, M.G.R., TAVARES, L.B.B., GARCÍA, J.A. Presencia de coliformes fecales, Escherichia coli y Staphylococcus aureus coagulasa y DNAsa positivos en queso. Revista Argentina de Microbiologia, Buenos Aires, v.30, n.1, p.8-12, 1998.

SABIONI, J.G., NASCIMENTO, D., PEREIRA, J.L. Intoxicação estafilocócica causada por queijo tipo Minas em Ouro Preto (MG), 1992. Higiene Alimentar, São Paulo, v.8, n.33, p.2223, set, 1994

SANTOS, F.A., NOGUEIRA, N.A.P., CUNHA, G.M.A Aspectos microbiológicos do queijo tipo "coalho" comercializado em Fortaleza - Ceará. B CEPPA, Curitiba, v.13, n.1, p.31-36, jan.-jun, 1995.

SHARF, J.M. Exame microbiológico de alimentos. São Paulo : Polígono, 1972. Cap.16: Índices de sanidade: p.173-186.

SILVA, C.A.M., LEITÃO, M.F. de F. Influência da temperatura de armazenamento na proliferação microbiana e no tempo de vida útil de queijo tipo "Minas Frescal". In: CONGRESSO BRASILEIRO DE CIÊNCIA E TECNOLOGIA DE ALIMENTOS, 4, 1980, Rio de Janeiro. Programa Oficial, Resumos... Rio de Janeiro : Sociedade Brasileira de Ciência e Tecnologia de Alimentos, 1980. p.186.

VANDERZANT, C., SPLITTSTOESSER, D.F. Compedium for the microbiological examination of foods. 3 ed. Washington : American Public Health Association, 1992, 1219 p.

Ciência Rural, v. 31, n. 6, 2001. 